\section{(C) OPEN ACCESS}

\title{
Stroke in a young man: a late complication of radiation therapy
}

\author{
Zhaozhi Jiang, ${ }^{1}$ Mitchell Elkind, ${ }^{2}$ Matthew Lucky, ${ }^{3}$ Zoltan Fekete ${ }^{4}$
}

'Graduate Medical Education, Orange Regional Medical Center, Middletown, New York, USA

${ }^{2}$ Department of Neurology, Vagelos College of Physicians and Surgeons, Columbia University, New York, New York, USA

${ }^{3}$ Graduate Medical Education, Orange Regional Medical Center, Middletown, New York, USA

${ }^{4}$ Crystal Run Healthcare, Rock Hill, New York, USA

Correspondence to

Zhaozhi Jiang,

zjiang@student.touro.edu

Accepted 17 January 2019

Check for updates

(c) BMJ Publishing Group Limited 2019. Re-use permitted under CC BY-NC. No commercial re-use. See rights and permissions. Published by BMJ.

To cite: Jiang $\mathrm{Z}$, Elkind $\mathrm{M}$, Lucky $\mathrm{M}$, et al. BMJ Case Rep 2019;12:e228029. doi:10.1136/bcr-2018228029

\section{SUMMARY}

This 37-year-old man presented with left sided facial warmth and numbness associated with new suddenonset right hemiparesis. The patient first developed sudden numbness of his left lip and warmth in left ear which travelled to the rest of left face. His past medical history was significant for hypertension, Hodgkin lymphoma treated with radiation therapy at the age of 10 , and sleeve gastrectomy for obesity 1 year ago complicated by bilateral ischaemic cerebral infarctions with residual left hemiparesis. No acute infarcts were found on MRI. Transesophageal echocardiography revealed a complex atheroma near the sinotubular junction in ascending aorta.

\section{BACKGROUND}

Stroke is the fifth leading cause of death and the leading cause of long-term disability in the USA. Nearly, three-quarters of all strokes occur in people over the age of 65 . Stroke in young patients is relatively rare but increasing. ${ }^{1}$ One of the reasons for stroke in the young can be a late complication of radiation therapy used in treating cancers, such as Hodgkin lymphoma. ${ }^{2}$ We describe a case of stroke in a young survivor of Hodgkin lymphoma treated with radiation therapy at the age of 10 .

\section{CASE PRESENTATION}

A 37-year-old man presented with complaints of left sided facial numbness and sensation of warmth in left face associated with new right-sided hemiparesis. He was working at his computer when he developed sudden numbness of his left lip and simultaneous feelings of right sided weakness. He then began to feel a sensation of warmness of his left face, starting in the ear and travelling to the rest of the face. On neurological examination, he had right-sided and left-sided weakness, with no changes in speech or mentation. The patient also reported a rash on the abdomen and right elbow for 1 week; he had been in urgent care and started on a prednisone taper. He was also diagnosed with colitis after left abdominal pain and was taking ciprofloxacin and metronidazole.

The patient had a history of chronic essential hypertension, hypothyroidism and Hodgkin lymphoma of left side of neck without metastasis at the age of 10 , which was treated with radiation of neck and chest as well as splenectomy; and sleeve gastrectomy complicated by bilateral ischaemic strokes 1 year ago with residual left arm and leg weakness. He had $180 \mathrm{lb}$ weight loss after surgery. Patient was on aspirin $81 \mathrm{mg}$ daily and atorvastatin $40 \mathrm{mg}$ daily since the stroke.

\section{INVESTIGATIONS}

On arrival, a head CT without contrast was performed, which revealed three chronic infarcts in the right MCA distribution and a chronic infarct involving the left medial occipital cortex, with no acute lesion.

Brain MRI revealed multiple wedge-shaped transcortical areas of encephalomalacia and gliosis bilaterally in the inferolateral right frontal lobe, right posterior frontal lobe, right parietal lobe and medial left occipital lobe, which correlates with his previous CVA (figure 1). MRA of neck showed no left internal carotid artery stenosis. ECG showed normal sinus rhythm, normal intervals and no ST or $\mathrm{T}$ wave changes. Continuous telemetric monitoring of the patient demonstrated normal sinus rhythm throughout the hospitalisation. Transthoracic echocardiography revealed mild aortic stenosis with mitral valve calcification. Transoesophageal echocardiography (TEE) found a complex atheroma, large, ulcerated and mobile, measuring 9-mm thickness near the sinotubular junction in ascending aorta. Hypercoagulability evaluation, including antiphospholipid antibodies, was negative.

\section{DIFFERENTIAL DIAGNOSIS}

The exact cause of his stroke-like symptoms was unclear. One possibility was cardiogenic ischaemic stroke. Another possibility was hypercoagulable state due to history of lymphoma. The third possibility was aortic stenosis secondary to radiation therapy. Seizure and migraine were the other two possibilities. SMART syndrome, ${ }^{34}$ which stands for stroke-like migraine attacks after radiation therapy, can also be a possible diagnosis but unlikely since the patient had no headache, only received chest radiation, no brain radiation therapy and the MRI of the brain without and with contrast revealed old chronic strokes and not SMART syndrome.

\section{TREATMENT}

The patient was given aspirin $325 \mathrm{mg}$ and his symptoms resolved within a couple hours. The patient started rivaroxaban and rosuvastatin for secondary prevention of cardioembolic stroke after complex aortic atheroma was found on TEE.

\section{OUTCOME AND FOLLOW-UP}

The patient was readmitted 2 months later with identical complaints of left facial numbness. MRI of 


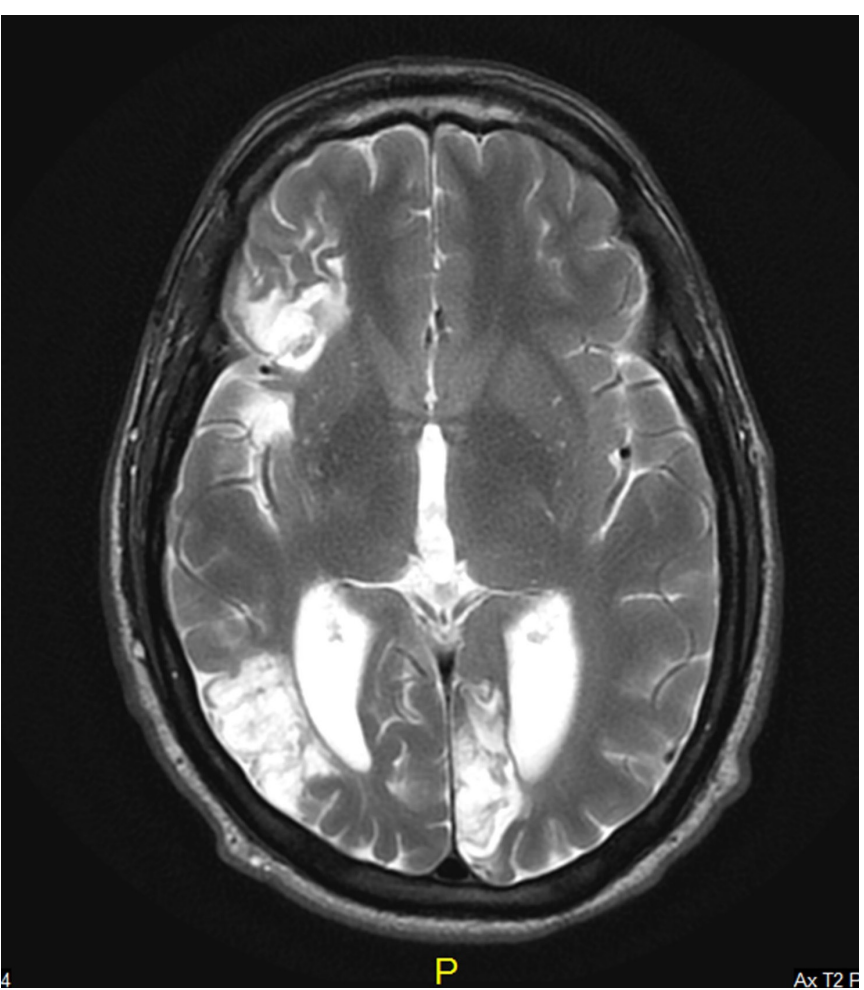

Figure $1 \mathrm{MRI}$ of the brain.

the brain again revealed no acute stroke. Patient was discharged on aspirin $81 \mathrm{mg}$ daily, rivaroxaban $20 \mathrm{mg}$ daily and rosuvastatin $5 \mathrm{mg}$ daily. Anticoagulation was subsequently stopped. Electroencephalogram was done to exclude seizures, and showed no epileptiform abnormalities. He started levetiracetam to prevent possible seizures.

\section{DISCUSSION}

Young adults account for $10 \%-15 \%$ of all stroke cases. ${ }^{5}$ Approximately 20\%-30\% of cerebral infarctions in a general population are the result of a cardioembolic source, while approximately $15 \%-20 \%$ of strokes are secondary to extracranial large vessel disease. ${ }^{6}$ Large-artery atherosclerosis has been shown to be an infrequent cause of ischaemic stroke in young adults, accounting for less than $10 \%$ of cases. ${ }^{5}$ Other common reasons for stroke in young adults include small vessel disease, hypercoagulability and miscellaneous other causes. The most common risk factors include smoking, dyslipidaemia and hypertension. ${ }^{7}$ Other less common causes of stroke in young adults include non-atherosclerotic angiopathies, hematologic conditions, genetic diseases and inflammatory and infectious conditions. ${ }^{5}$

Our patient was found to have a complex atheroma measuring 9-mm thickness near the sinotubular junction, which is possibly a late complication of radiation. Other risk factors for atheroma include smoking, hypercholesterolaemia, hypertension, obesity and diabetes.

Aortic plaque $4 \mathrm{~mm}$ or larger is an independent risk factor for ischaemic stroke. Stroke risk is greater for complex, mobile plaques larger than $5 \mathrm{~mm} .{ }^{6}$ TEE is the preferred test for diagnosis of aortic atherosclerosis. Although atherosclerosis can be seen in young patients, the clinical presentations are usually not seen until patients are older. Young patients without conventional cardiac risk factors who received mediastinal irradiation for Hodgkin lymphoma can present with coronary artery disease (CAD) in their 20s. ${ }^{2}$

Radiation therapy, an essential method to treat Hodgkin lymphoma, helped improved the overall prognosis, but can be associated with serious complications. There is a 5- to 17-fold greater risk of cerebrovascular events (stroke or transient ischaemic attack) in patients with head and neck cancer who are treated with RT compared with matched non-RT treated controls. ${ }^{8}$ A multi-institutional cohort study of more than 5-year cancer survivors diagnosed between 1970 and 1986 showed survivors of childhood Hodgkin disease are at increased risk of stroke. The incidence of late-occurring stroke among HD survivors was 83.6 per 100000 person-years, significantly higher than expected range of 10-23 per 100000 person-years in adults aged 18-44 years in the general population. ${ }^{9}$ Another retrospective study showed among 415 Hodgkin lymphoma survivors treated with radiation therapy, 42 patients (10.4\%) developed coronary artery disease at a median of 9 years after treatment, 30 patients $(7.4 \%)$ developed carotid and/or subclavian artery disease at a median of 17 years after treatment, and 25 patients (6.2\%) developed clinically significant valvular dysfunction at a median of 22 years. ${ }^{10}$ However, there is no evidence of aortic disease in the above studies.

Radiation-induced arterial injury may involve any arteries exposed to radiation. We speculate that in our case, radiation therapy contributed to development of a complex aortic atheroma. The exact mechanism of radiation therapy causing aortic atheroma remains unclear. It is widely accepted that neck and chest radiation can lead to carotid atherosclerosis and coronary atherosclerosis, thus increases the risk of stroke. The review by $\mathrm{Xu}$ and $\mathrm{Cao}$ suggests endothelial dysfunction, injury and occlusion of vasa vasorum and accelerated atherosclerosis be the most likely cause of carotid stenosis. ${ }^{11}$ The review by Jaworski et al reveals endothelial dysfunction is a precipitating factor in the development of radiation induced cardiac disease. ${ }^{12}$ The review by Darby et al suggests radiation induced coronary artery disease results from intimal proliferation of myofibroblasts with lipid-containing macrophages forming atherosclerotic plaques. ${ }^{2}$ Radiation induced aortic atheroma, as a process of aortic atherosclerosis, is likely caused by endothelial damage with plaque formation, thus causes embolic stroke. The study by Stewart et al suggests ionising radiation accelerates the development of macrophage-rich and inflammatory atherosclerotic lesions in $\mathrm{ApoE}^{-/-}$mice; lesions developed in the aortic roots of irradiated mice were macrophage rich and lipid filled, whereas lesions in non-irradiated mice were collagenous and only minimal macrophage infiltration. ${ }^{13}$

Management of cerebrovascular disease associated with radiation-induced vascular injury still needs further study. Evidencebased guidelines for the management of asymptomatic and symptomatic (medium- and large-artery) radiation vasculopathy are lacking. ${ }^{14}$

In patients who had a stroke with large-artery atherosclerosis or small-vessel disease, antiplatelet drugs are recommended. Acetylsalicylic acid (ASA) should be a first-choice antiplatelet drug in secondary prevention. ${ }^{5}$ ASA in combination with dipyridamole or clopidogrel monotherapy can also be used as the first-line treatment. ${ }^{15}$ The combination of ASA and clopidogrel can reduce the risk of stroke in the first 90 days and does not increase the risk haemorrhage. ${ }^{16}$

Thanks to Emmanuel Obeng Nketiah MD for doing and interpreting the TEE. 


\section{Learning points}

- Radiation therapy for lymphoma is often successful, and therefore there are likely to be more and more lymphoma survivors in the community. One of the possible complications of chest radiation therapy may be vascular injury of the aorta with consequent unstable mobile or ulcerated atheroma, as in the case of our young patient.

- One should consider this complication in young patients who had a stroke with history of chest radiation, even when remote.

- Complex aortic atheroma may be a cause of stroke. The role of early screening for aortic atheroma in patients with prior chest radiation requires further study.

Contributors ZJ, ME and ZF contributed to the design of the case report. ZJ drafted the manuscript. ME, ML and ZF revised the manuscript for important intellectual content. ZF contributed to the final approval of the version to be published. ML obtained the informed consent from the patient.

Funding The authors have not declared a specific grant for this research from any funding agency in the public, commercial or not-for-profit sectors.

Competing interests None declared.

Patient consent for publication Obtained.

Open access This is an open access article distributed in accordance with the Creative Commons Attribution Non Commercial (CC BY-NC 4.0) license, which permits others to distribute, remix, adapt, build upon this work non-commercially, and license their derivative works on different terms, provided the original work is properly cited and the use is non-commercial. See: http://creativecommons.org/ licenses/by-nc/4.0/

\section{REFERENCES}

1 George MG, Tong X, Bowman BA. Prevalence of cardiovascular risk factors and strokes in younger adults. JAMA Neurol 2017;74:695-703.
2 Darby SC, Cutter DJ, Boerma M, et al. Radiation-related heart disease: current knowledge and future prospects. Int I Radiat Oncol Biol Phys 2010;76:656-65.

3 St-Amant M, Gaillard F, et al. SMART syndrome [Internet]. https://radiopaedia.org/ articles/smart-syndrome (cited 10 July 2018).

4 Singh AK, Tantiwongkosi B, Moise AM, et al. Stroke-like migraine attacks after radiation therapy syndrome: Case report and review of the literature. Neuroradiol J 2017;30:568-73

5 Smajlović D. Strokes in young adults: epidemiology and prevention. Vasc Health Risk Manag 2015;11:157-64.

6 Mowzoon N, Flemming KD. Chapter 11, Cerebrovascular disease. In. Neurology board review: an illustrated study guide. Rochester: Mayo Foundation for Medical Education and Research, 2007:435-84.

7 Putaala J, Metso AJ, Metso TM, et al. Analysis of 1008 consecutive patients aged 15 to 49 with first-ever ischemic stroke: the Helsinki young stroke registry. Stroke 2009:40:1195-203.

8 Addison D, Lawler PR, Emami H, et al. Incidental statin use and the risk of stroke or transient ischemic attack after radiotherapy for head and neck cancer. J Stroke 2018;20:71-9

9 Bowers DC, McNeil DE, Liu Y, et al. Stroke as a late treatment effect of Hodgkin's Disease: a report from the Childhood Cancer Survivor Study. J Clin Oncol 2005:23:6508-15.

10 Hull MC, Morris CG, Pepine CJ, et al. Valvular dysfunction and carotid, subclavian, and coronary artery disease in survivors of hodgkin lymphoma treated with radiation therapy. JAMA 2003;290:2831-7.

$11 \mathrm{Xu}$ J, Cao Y. Radiation-induced carotid artery stenosis: a comprehensive review of the literature. Interv Neurol 2014;2:183-92.

12 Jaworski C, Mariani JA, Wheeler G, et al. Cardiac complications of thoracic irradiation. J Am Coll Cardiol 2013:61:2319-28.

13 Stewart FA, Heeneman S, Te Poele J, et al. lonizing radiation accelerates the development of atherosclerotic lesions in $\mathrm{ApoE}^{-1-}$ mice and predisposes to an inflammatory plaque phenotype prone to hemorrhage. Am J Pathol 2006;168:649-58.

14 Plummer C, Henderson RD, O'Sullivan JD, et al. Ischemic stroke and transient ischemic attack after head and neck radiotherapy: a review. Stroke 2011;42:2410-8.

15 Kernan WN, Ovbiagele B, Black HR, et al. Guidelines for the prevention of stroke in patients with stroke and transient ischemic attack: a guideline for healthcare professionals from the American Heart Association/American Stroke Association. Stroke 2014;45:2160-236.

16 Wang $Y$, Wang $Y$, Zhao $X$, et al. Clopidogrel with aspirin in acute minor stroke or transient ischemic attack. N Engl J Med 2013;369:11-19.

Copyright 2019 BMJ Publishing Group. All rights reserved. For permission to reuse any of this content visit

https://www.bmj.com/company/products-services/rights-and-licensing/permissions/

BMJ Case Report Fellows may re-use this article for personal use and teaching without any further permission.

Become a Fellow of BMJ Case Reports today and you can:

- Submit as many cases as you like

- Enjoy fast sympathetic peer review and rapid publication of accepted articles

- Access all the published articles

- Re-use any of the published material for personal use and teaching without further permission

For information on Institutional Fellowships contact consortiasales@bmjgroup.com

Visit casereports.bmi.com for more articles like this and to become a Fellow 